\title{
Overuse and underuse of calcium and vitamin D in women with osteoporosis: A survey in a primary care setting
}

\author{
Milagros Silva, Adam Romeiser, David W. Baker, Aashish K. Didwania, Tiffany Brown, \\ Joseph M. Feinglass, Ji Young Lee, Nancy C. Dolan*
}

Division of General Internal Medicine, Department of Medicine, Northwestern University Feinberg School of Medicine, Chicago, USA; ${ }^{*}$ Corresponding Author: ndolan@nmff.org

Received 18 September 2013; revised 2 November 2013; accepted 3 December 2013

Copyright (C) 2013 Milagros Silva et al. This is an open access article distributed under the Creative Commons Attribution License, which permits unrestricted use, distribution, and reproduction in any medium, provided the original work is properly cited.

\section{ABSTRACT}

Introduction: Optimal calcium and vitamin D intake is important components of the treatment of osteoporosis. The national average calcium and vitamin $D$ intake for women over age $\mathbf{5 0}$ is below the recommended levels for optimal bone health. The aim of this study was to assess whether deficiencies in calcium and vitamin D intake exist in women with osteoporosis in a general medicine practice, as well as evaluate whether physicians accurately document calcium and vitamin D supplementation in the health record. Methods: Using the Electronic Health Record (EHR), we identified all female patients age $\mathbf{5 0}$ and older with the diagnosis of osteoporosis who were seen at the study site clinic, an urban academic general medicine practice, between January $1^{\text {st }}, 2010$ and December $1^{\text {st }}, 2010$. Women were randomly selected to receive an invitation to participate in a telephone survey on osteoporosis treatment. Results: One hundred and sixteen women completed the telephone survey. The mean calcium intake was 1524 mg per day. Forty-nine percent of women surveyed reported taking less than $1200 \mathrm{mg} /$ day of supplemental calcium. When considering reported calcium intake from diet, $33 \%$ percent consumed less than $1200 \mathrm{mg} /$ day and 52\% percent consumed more than $1500 \mathrm{mg} /$ day. Twenty eight percent of patients were taking less than $\mathbf{8 0 0}$ IU/day of vitamin D; only four percent were taking more than $\mathbf{4 0 0 0}$ IU/day. Agreement between patients' self-reported intake of calcium, vitamin D and multivitamin supplements and physicians' documentation of these supplements was $52 \%$ for calcium,
$53 \%$ for vitamin D and $61 \%$ for multivitamin. Conclusion: Among women with osteoporosis getting regular care in a general medicine practice, approximately a third are getting less than the recommended daily amount of calcium and a quarter less than the recommended amount of vitamin D. In addition, a significant proportion of women are getting excessive daily amounts of calcium, which may also be a quality concern. Rates of agreement between self-reported calcium and vitamin D supplements and chart documentation of these supplements were low.

Keywords: Calcium Supplementation; Ambulatory; Electronic Health Record; Vitamin Supplementation; Osteoporosis

\section{INTRODUCTION}

Osteoporosis is a major public health problem affecting more than 10 million Americans [1]. Fractures, which can lead to disability, chronic pain, functional impairment and increased mortality, are the most concerning complication of osteoporosis. Osteoporosis and related fractures resulted in an estimated $\$ 22$ billion in medical costs in 2008 [2].

Adequate calcium and vitamin D intake is important for bone health. Guidelines about whether or not average risk postmenopausal women should take vitamin D and calcium supplements to prevent osteoporotic fractures however are conflicting [1,3]. Supplementation with vitamin D and calcium increases the risk of renal stones, while the benefits of preventing fractures in average risk postmenopausal women are inconsistent [4,5]. The US Preventive Services Task Force, recently recommended against the use of 400 IU or less of vitamin D and 1000 
mg or less of calcium supplementation for the primary prevention of fractures in postmenopausal women and concludes there is insufficient evidence to recommend higher doses of calcium and vitamin D [3].

Adequate calcium and vitamin $\mathrm{D}$ intake, through diet and/or supplements, however, is critical for prevention of fractures in women with established osteoporosis [6-8]. A review of studies that led to the FDA approval of prescription medications used for the treatment of osteoporosis found that $80 \%$ of studies had been performed under conditions where a certain minimum calcium and vitamin D intake was ensured [6]. One cannot conclude that these prescription medications would be as effective in calcium and vitamin $\mathrm{D}$ deficient patients.

The National Osteoporosis Foundation (NOF) currently recommends that women with osteoporosis older than age 50 consume $1200 \mathrm{mg}$ per day of elemental calcium and 800 IU of vitamin D [1]. The National Health and Nutrition Examination Survey (NHANES) 20052006 estimated the vitamin D intake for women with osteoporosis aged 51 and above to be approximately 400 IU/day with supplements. The reported median calcium intake was $433 \mathrm{mg}$ per day for calcium supplement nonusers and $1319 \mathrm{mg}$ for calcium supplement users. Overall, only $40 \%$ of osteoporosis patients had calcium intake of at least $1200 \mathrm{mg} / \mathrm{d}[9,10]$.

The purpose of the current study was to determine whether similar deficiencies of calcium and vitamin D intake existed in postmenopausal women with osteoporosis getting care in a general medicine practice. A secondary aim was to assess agreement between physicians' documentation of calcium and vitamin D supplements in patients' records and self-reported intake.

\section{METHODS}

\subsection{Study Design}

The study was a telephone survey of a random sample of female patients age 50 and older with a diagnosis of osteoporosis receiving regular care at a single urban academic general internal medicine practice. All physiccians in the practice use Epic, a comprehensive electronic health record (EHR) for all clinical encounters including documentation and order entry. The Institutional Review Board (IRB) of Northwestern University Feinberg School of Medicine approved this study.

\subsection{Survey Instrument}

We developed a telephone survey based on consultation with two physicians specialized in bone health, a Ph.D. in communication skills and an expert in survey development. The survey included questions about osteoporosis treatment, knowledge of recommended daily intake of calcium and vitamin $\mathrm{D}$ for women age 50 and older, supplements taken at home, name, dosage and frequency of calcium, vitamin $\mathrm{D}$ or multivitamin, and type and amount of dietary calcium intake. Questions on the type and amount of dietary calcium consumption were adapted from the NOF questionnaire [1]. Prior to implementation, the survey was tested for comprehension and duration.

\subsection{Participants}

Using an EHR query, we identified all female patients age 50 and older with the diagnosis of osteoporosis who were seen at the study site clinic, an urban academic general medicine practice, between January $1^{\text {st }}, 2010$ and December $1^{\text {st }}, 2010$. We defined regular care as two or more visits within the last 18 months. A random order list of women was generated from the 1028 potentially eligible women initially identified. An electronic communication was sent to the primary care physician of each patient to notify them of the study and to provide them with names of their patients potentially eligible for the study. These physicians were asked to notify the investigators if any of their patients were non-English speaking, had a diagnosis of dementia or were deemed not appropriate for study. Letters were sent to the remaining patients notifying them of the study and providing them with a number to call to opt-out of study recruitment.

\subsection{Telephone Survey and EHR Review}

Two of the study investigators (MS and TB) conducted the telephone surveys from April through August of 2011. Patients were called sequentially until the predetermined target of approximately 100 completed surveys, roughly $10 \%$ of the initial sample, was met. At least three attempts were made to contact each patient on a randomly ordered list. Verbal consent of patients was obtained over the phone prior to conducting the survey; they were informed that their responses would not affect their routine care. Prior to asking any survey questions, the interviewer asked patients to retrieve all their medication bottles including supplements for reference. If the patient had any clinical questions, they were referred to the patient's physician.

We queried the EHR of those patients who completed the survey for information on demographics, medical diagnoses, office visits and medications.

\subsection{Statistical Analysis}

Means, daily amounts and standard deviation were calculated for calcium supplementation, dietary calcium and vitamin D. The amount of calcium intake per day was categorized into three groups: insufficient calcium intake (less than $1200 \mathrm{mg}$ per day), adequate calcium 
intake (1200 to $1500 \mathrm{mg}$ per day), and excessive calcium intake (above $1500 \mathrm{mg}$ per day) [1]. The amount of vitamin D intake per day was also categorized into insufficient vitamin D intake (less than 800 IU per day), adequate vitamin D intake (800 to 4000 IU per day) and excessive vitamin D intake (above 4000 IU per day) [1]. The Fisher-Exact test was performed to test whether there was a statistically significant association between the amount of calcium or vitamin D intake and patient's race, usage of bisphosphonates or knowledge of recommended amount of intake. A Mann-Whitney test was performed to test the association of level of intake with age. Percent agreement and kappa between patient's selfreported calcium, vitamin $\mathrm{D}$, and multivitamin supplements and chart documentation were also calculated.

\section{RESULTS}

\subsection{Survey Completion and Patient Characteristics (Table 1)}

Of 357 randomly selected patients, 50 were deemed not appropriate for contact by their primary care physicians and 20 patients opted out after receiving letters describing the study. We called the 287 remaining patients; 253 were reached and 116 completed surveys. Based on the American Association for Public Opinion Research (AAPOR) calculation [11], a response rate of $50.2 \%$ was obtained. The mean age of survey participants was $70.5(\mathrm{SD}=9.4)$. Sixty nine $(60 \%)$ were White/ other, thirty-three (28\%) African American and fourteen (12\%) declined to answer. Compared to women who completed the survey, women who did not complete the survey were similar with respect to age and race.

\subsection{Calcium and Vitamin D Knowledge and Supplementation}

Over $90 \%$ of patients were aware of the effects of calcium and vitamin $\mathrm{D}$ on bone strength and reported taking calcium, vitamin D or multivitamin supplements. However, approximately $75 \%$ of women were unaware of or incorrectly answered the question about the recommended amounts of calcium and vitamin D they should be getting. Ninety five percent of women reported taking a calcium or vitamin D supplement. Forty-nine percent were taking less than $1200 \mathrm{mg}$ of calcium through supplements or multivitamins. However, when calcium from food was taken into account, this decreased to $33 \%$. The fourteen patients who reported not taking any supplements or being unaware if they were taking them had a median intake of $472 \mathrm{mg}$ of calcium per day through diet alone $(\mathrm{SD}=345)$. Fifty two percent were getting more than the recommended amount of calcium a day (Table 2). Approximately $27 \%$ of women were getting less than the recommended vitamin D intake; few were taking
Table 1. Clinical characteristics $(\mathrm{n}=116)$.

\begin{tabular}{lc}
\hline Characteristic & Mean N (\%) \\
\hline Race & \\
Caucasian & $61(53)$ \\
African American & $33(28)$ \\
Hispanic & $3(3)$ \\
Other & $3(3)$ \\
Declined & $2(1)$ \\
Asian/Pacific Islander & $14(12)$ \\
Age & $70.5 \pm 9.4$ \\
Number of oral medications taken daily & $11.6 \pm 6.9$ \\
Number of visits to General Internal Medicine in & $3.5 \pm 2.5$ \\
2010 & \\
Number of participants taking calcium or vitamin & \\
D supplements and/or multivitamin & \\
Yes & $110(95)$ \\
No & $5(4)$ \\
Unsure & $1(1)$ \\
Number of participants taking osteoporosis & \\
treatment medication & \\
Yes & \\
No & $61(53)$ \\
Self-reported type of osteoporosis treatment & $55(47)$ \\
Bisphosphonate & \\
Calcitonin salmon & $53(46)$ \\
Teriparatide & $1(1)$ \\
Raloxifene & $5(4)$ \\
Unsure & $1(1)$ \\
\hline & \\
&
\end{tabular}

Table 2. Reported daily calcium intake $(\mathrm{n}=116)$.

\begin{tabular}{cccc}
\hline $\begin{array}{c}\text { Calcium } \\
(\mathrm{mg} / \text { day })\end{array}$ & $\begin{array}{c}\text { Supplement } \\
\mathrm{N}(\%)\end{array}$ & $\begin{array}{c}\text { Supplement and diet } \\
\mathrm{N}(\%)\end{array}$ & $\begin{array}{c}\text { Diet } \\
\mathrm{N}(\%)\end{array}$ \\
\hline None & $14(12.1)$ & - & - \\
$<1200$ & $57(49.1)$ & $38(32.8)$ & $111(95.7)$ \\
$1200-1500$ & $27(23.3)$ & $18(15.5)$ & $2(1.7)$ \\
$>1500$ & $18(15.5)$ & $60(51.7)$ & $3(2.6)$ \\
\hline
\end{tabular}

excessive amounts of vitamin D (Table 3).

Patients' age, race, concomitant use of bisphosphonates and knowledge of the recommended amount of daily calcium were not significantly associated with the appropriate daily amount of calcium intake (Table 4). However, there was a trend toward women who were knowledgeable about the recommended daily amount of calcium intake being more likely to be getting more than $1500 \mathrm{mg}$ a day of calcium through diet and supplementation compared to those who were not knowledgeable ( $p$ value $=0.06$ ). Women who were knowledgeable about the recommended daily amount of vitamin D were more 
likely to be taking sufficient amounts of vitamin D ( $p$ value $=0.01)$. Women's age, race and bisphosphonate use were not associated with the likelihood of appropriate vitamin D intake (Table 4).

\subsection{Agreement between Self-Report and EHR}

Agreement between patients' self-reported intake of calcium, vitamin D and multivitamin supplements and physicians' documentation of these supplements was $52 \%$ for calcium, $53 \%$ for vitamin D and $61 \%$ for multivitamin. The kappa coefficient was 0.01 for calcium, -0.06 for vitamin D. Agreement was even lower between patient self-report and documentation of the type and dose of calcium, vitamin D and multivitamin.

\section{DISCUSSION}

In this study of women 50 and older with osteoporosis, almost all interviewed were aware of the importance of calcium and vitamin D for bone health, but approximately one third reported inadequate total daily calcium and one quarter inadequate supplementation of vitamin D. Interestingly, we also found that half of women were getting more than the recommended daily total amount of calcium, when considering both dietary and supplemental calcium intake. Because of the known risk of kidney stones with calcium supplement intake above $1500 \mathrm{mg}[1,4,5]$ and emerging concerns that calcium supplementation is associated with increased risk of myocardial infarction [12], excessive calcium intake is also a potential quality and safety concern.

Age, race, use of bisphosphonates and knowledge of the recommended amount of calcium and vitamin D were not associated with taking adequate daily amounts of calcium and vitamin D. The trend toward women who were knowledgeable about calcium intake being more likely to have excessive daily intake suggests that many women do not necessarily consider their dietary calcium when deciding how much calcium supplement they should take.

Daily calcium intake among women with osteoporosis in our study of general medicine patients is higher than reported in the 2005-2006 NHANES. This survey found $64 \%$ of women reported using calcium-containing supplements, and of these only $40 \%$ met the recommended calcium intake of at least $1200 \mathrm{mg}$ [9]. By comparison, in our study, $95 \%$ of women reported taking calcium, vitamin D or multivitamin supplements and $67 \%$ were getting at least $1200 \mathrm{mg}$ per day. The higher percentage of calcium intake among women in our study is likely due in part to differences in study population as well as temporal trends since 2005-2006.

To our knowledge, this is the first study to compare a patient's reported daily amount of calcium and vitamin D

Table 3. Reported daily supplemental vitamin D intake $(\mathrm{n}=$ 114).

\begin{tabular}{cc}
\hline Vitamin D (IU/day) & $\mathrm{N}(\%)$ \\
\hline$<800$ & $31(27.2)$ \\
$800-4000$ & $74(64.9)$ \\
$>4000^{*}$ & $5(4.4)$ \\
Unsure & $4(3.5)$ \\
\hline
\end{tabular}

${ }^{*}$ Two patients taking therapeutic doses of vitamin D (50,000 IU) were excluded.

Table 4. Comparison of patients taking insufficient, adequate, excessive amounts of calcium and vitamin D with race, age, knowledge of recommended intake and use of bisphosphonate $(n=116)$.

\begin{tabular}{|c|c|c|c|c|c|c|}
\hline & \multicolumn{3}{|c|}{ Calcium (\%) } & \multicolumn{3}{|c|}{ Vitamin D $(\%)^{\dagger}$} \\
\hline & Insufficient & Adequate & Excessive & Insufficient & Adequate & Excessive \\
\hline \multicolumn{7}{|l|}{ Race } \\
\hline White/other & 21.6 & 12.1 & 37.9 & 20.0 & 50.0 & 2.7 \\
\hline African-American & 12.1 & 3.4 & 12.9 & 8.2 & 17.3 & 1.8 \\
\hline \multicolumn{7}{|l|}{ Age } \\
\hline$<65$ & 10.3 & 6.1 & 12.9 & 10.9 & 13.4 & 2.7 \\
\hline$\geq 65$ & 23.3 & 9.5 & 37.9 & 17.3 & 23.6 & 3.6 \\
\hline \multicolumn{7}{|l|}{ Knowledge } \\
\hline Correct & 4.3 & 3.5 & 17.2 & 1.8 & 20.0 & 2.7 \\
\hline Incorrect & 29.3 & 12.1 & 33.6 & 26.4 & 47.3 & 1.8 \\
\hline \multicolumn{7}{|l|}{ Bisphosphonate use } \\
\hline Yes & 17.2 & 7.8 & 28.4 & 15.5 & 36.4 & 1.8 \\
\hline No & 16.4 & 7.8 & 22.4 & 12.7 & 30.9 & 2.7 \\
\hline
\end{tabular}

\footnotetext{
${ }^{\dagger}$ Four patients who were unsure of their vitamin D intake and two patients taking therapeutic doses of vitamin D (50,000 IU) were excluded.
} 
supplementation with what is recorded in their medical record. Our study shows that there is low percent agreement between the patients' report of calcium, vitamin D, and multivitamin supplementation and physician documentation of these supplements. This is consistent with previous studies that have documented that it is common for medication lists in an EHR to have inaccuracies, especially with regard to medications that are available over the counter $[13,14]$. One study showed that $43 \%$ of the medications listed in the EHR were inaccurate and more than three times as many over-the-counter drugs than prescription medications were missing from the EHR [13].

Our study has several limitations. This was a single-center study and may not be generalizable to other practices. Patients who refused to participate in the study could affect the results in unpredictable ways, potentially leading to selection bias. Those who interviewed are thought to represent the general clinical population, making selection bias less of a concern. The survey instrument was an original questionnaire and we were not able to validate participant responses. We used a simplified approach to assess dietary calcium intake, rather than an extensive food recall or dietary assessment, based on the NOF guidelines. While this might underestimate dietary calcium intake, a quick assessment tool such as the one used, is more amenable to general use in an office setting than a more extensive assessment tool. Our survey did not ask about dietary vitamin D since vitamin D is found in only a few foods and dietary intake in the US is low $[8,9]$. Nonetheless, we might have underestimated total daily vitamin $\mathrm{D}$ intake in our patient population.

Our results emphasize that reporting the average daily intake of calcium for a population is misleading because there is a bimodal distribution of calcium intake. While many patients have inadequate calcium intake, many others have excessive calcium intake. There appears to be little association between knowledge of adequate daily amount of calcium and vitamin D and taking the recommended amounts. Failure of physicians and patients to take into account dietary calcium intake may account for the overuse of calcium supplements in some patients. The discrepancy between calcium and vitamin D supplement use reported by patients and what is documented in the health record highlight the need for improved communication with patients.

In order to counsel women on the appropriate amount of calcium supplementation, physicians first need to assess a patient's current dietary calcium intake. Incorporating a calcium intake assessment in the EHR could help facilitate this evaluation and potentially help reduce both deficient and excessive calcium intake. A similar assessment could be done for vitamin $\mathrm{D}$, although dietary vitamin $\mathrm{D}$ is less likely to be an important factor in over- all vitamin D intake $[8,9,15]$.

Regular assessment of a patient's vitamin D and calcium intake, clear recommendations about what, if any, supplements they should be taking, and accurate documentation of supplementation in the medical record, would improve the quality of care of patients with osteoporosis in the outpatient setting.

\section{ACKNOWLEDGEMENTS}

We thank Kenzie Cameron, Ph.D. for her help with survey development.

\section{REFERENCES}

[1] National Osteoporosis Foundation (2013) Clinician's guide to prevention and treatment of osteoporosis. National Osteoporosis Foundation (NOF), Washington DC. http://www.nof.org

[2] Blume, S.W. and Curtis, J.R. (2011) Medical costs of osteoporosis in the elderly medicare populations. Osteoporosis International, 6. 1835-1844. http://dx.doi.org/10.1007/s00198-010-1419-7

[3] Moyer, V.A. on Behalf of the US Preventive Services Task Force (2013) Vitamin D and calcium supplementation to prevent fractures. Annals of Internal Medicine, 158, 691-696.

[4] Mei Chung, M., Lee, J., Terasawa, T., Lau, J. and Trikalinos, T.A. (2011) Vitamin D with or without calcium supplementation for prevention of cancer and fractures: An updated meta-analysis for the US Preventive Services Task Force. Annals of Internal Medicine, 155, 827-838. http://dx.doi.org/10.7326/0003-4819-155-12-201112200$\underline{00005}$

[5] Wallace, R.B., Wactawski-Wende J., O'Sullivan, M.J., et al. (2011) Urinary tract stone occurrence in the Women's Health Initiative (WHI) randomized clinical trial of calcium and vitamin D supplements. American Journal of Clinical Nutrition, 94, 270-277. http://dx.doi.org/10.3945/ajen.110.003350

[6] Boonen, S., Vanderschueren, D., Haentjens, P. and Lips, P. (2006) Calcium and vitamin D in the prevention and treatment of osteoporosis: A clinical update. Journal of Internal Medicine, 259, 539-552. http://dx.doi.org/10.1111/j.1365-2796.2006.01655.x

[7] Boonen, S., Lips, P., Bouillon, R., Bischoff-Ferrari, H.A., Vanderschueren, D. and Haentjens, P. (2007) Need for additional calcium to reduce the risk of hip fracture with vitamin D supplementation: evidence from a comparative meta-analysis of randomized controlled trials. Journal of Clinical Endocrinology \& Metabolism, 92, 1415-1423. http://dx.doi.org/10.1210/jc.2006-1404

[8] Sunyecz, J.A. and Weisman, S.M. (2005) The role of calcium in osteoporosis drug therapy. Journal of Women's Health, 14, 180-192. http://dx.doi.org/10.1089/jwh.2005.14.180

[9] Bailey, R.L., Dodd, K.W., Goldman, J.A., et al. (2010) Estimation of total usual calcium and vitamin D intakes 
in the Unites States. Journal of Nutrition, 140, 817-822. http://dx.doi.org/10.3945/jn.109.118539

[10] Stafford, R.S., Drieling, R.L., Johns, R. and Ma, J. (2005) National patterns of calcium use in osteoporosis in the United States. Journal of Reproductive Medicine, 50, 885-890.

[11] American Association for Public Opinion Research (2011) Standard definitions.

http://www.aapor.org/Standard Definitions2.htm

[12] Bolland, M.J., Avenell, A., Baron, J.A., et al. (2010) Effect of calcium supplements on risk of myocardial infarcttion and cardiovascular events: Meta-analysis. British Medical Journal, 341, 3691. http://dx.doi.org/10.1136/bmj.c3691

[13] Staroselsky, M., Volk, L.A., Tsurikova, R., et al. (2008)
An effort to improve electronic health record medication list accuracy between visits: Patients' and physicians' response. International Journal of Medical Informatics, 77, $153-160$

http://dx.doi.org/10.1016/j.ijmedinf.2007.03.001

[14] Stewart, S., Giannini, S., Bianchi, G., et al. (2009) Vitamin D status and response to treatment in post-menopausal osteoporosis. Osteoporosis International, 20, 239 244.

http://dx.doi.org/10.1007/s00198-008-0650-y

[15] Holick, M.F., Binkley, N.C., Bischoff-Ferrari, H.A., et al. (2012) Guidelines for preventing and treating vitamin D deficiency and insufficiency revisited. Journal of Clinical Endocrinology \& Metabolism, 97, 1153-1158.

http://dx.doi.org/10.1210/ic.2011-2601 